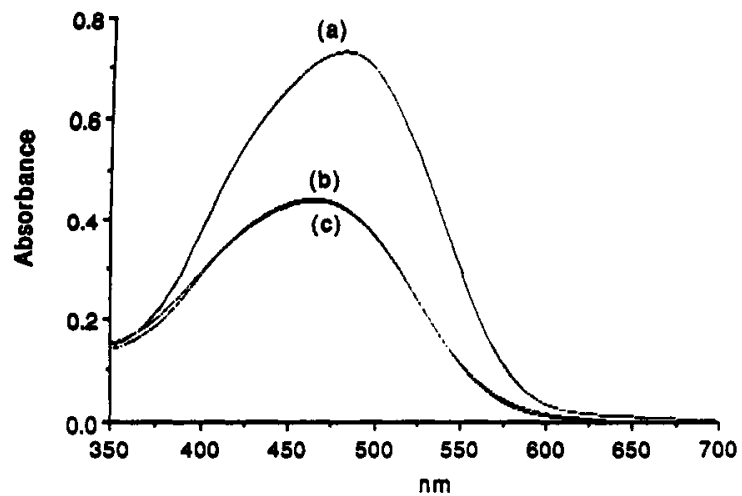

Figure 5. UV-vis absorption spectra of A204/ASD, from top to bottom: (a) pristine; (b) right after poling/curing; (c) poled/cured samples, thermal treatment at $100^{\circ} \mathrm{C}$ for $40 \mathrm{~h}$.

changed under ambient condition for at least $40 \mathrm{~h}$, time to which these measurements were carried out.

To investigate the absorption behavior as a function of time, the absorption spectrum at $100^{\circ} \mathrm{C}$ was taken at regular intervals over $40 \mathrm{~h}$ for poled/cured A204/DR1. An absorption peak at $\lambda_{\max }=508 \mathrm{~nm}$ existed before poling/curing. After poling/curing $\lambda_{\max }$ shifts to $493 \mathrm{~nm}$ with a decrease of absorbance. During the next $40 \mathrm{~h}, \lambda_{\max }$ shifted back toward longer wavelengths with a slight decrease in absorbance (Figure 4). It is important to note that the dye absorption spectrum shape is similar to the spectrum obtained before the curing cycle. This confirms that the azo dye left in the cured film has not degraded during the curing cycle.

For A204/ASD, the absorption spectrum was also taken regularly at $100^{\circ} \mathrm{C}$ over $40 \mathrm{~h}$. Immediately after poling/curing, a decrease in absorbance was observed. The absorption peak of the disperse orange 3 chromophore $\left(\lambda_{\max }=480 \mathrm{~nm}\right)$ shifted toward shorter wavelength, $\lambda_{\max }$ $=464 \mathrm{~nm}$ (Figure 5). During the next $40 \mathrm{~h}$, the absorption spectrum remained unchanged. This result suggests that the dye/polymer system did not degrade or sublime throughout the whole period of thermal treatment.

In conclusion, we have shown that a guest-host system based on cross-linked phenylsiloxane polymer and alkoxysilane dye has excellent room-temperature stability and a slow decay at $100^{\circ} \mathrm{C}$ in a period of $40 \mathrm{~h}$. The stability of second-order susceptibility achieved in this work is limited by the NLO chromophore degradation temperature. Curing at higher temperatures is clearly expected to lead to higher stability. However the A204/ASD thin film showed a much more stable second-order response compared to A204/DR1.

Acknowledgment. Partial financial support from ONR is gratefully acknowledged.

\section{Molecular Sieve Sensors for Selective Ethanol Detection}

Yongan Yan and Thomas Bein*

Department of Chemistry, Purdue University West Lafayette, Indiana 47907

Received March 9, 1992

Revised Manuscript Received June 16, 1992

Chemical microsensors play an increasing role in the area of environmental monitoring and industrial processing. ${ }^{1}$

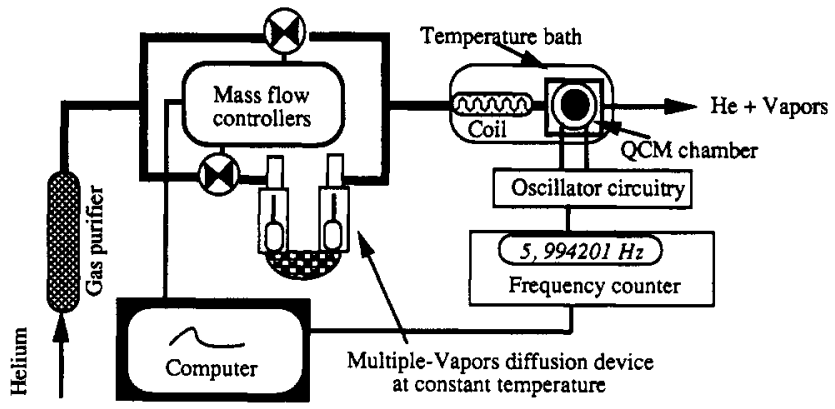

Figure 1. Schematic diagram of the apparatus for multiple vapor sorption experiments with the microsensor.

We have recently developed microsensors with molecular sieving functions in chemically selective layers on piezoelectric devices. ${ }^{2-4}$ Here we report the development of a chemical microsensor with combined molecular sieve and selective surface interactions, based on novel silicalite-silica composite thin films on the active areas of quartz crystal microbalances (QCMs).

In addition to the high sensitivity and selective size exclusion offered by molecular sieve micropore films, the nature of the chemical surface interactions is important. In the thin films described below, interference from water $(2.65 \AA)$ which is smaller than ethanol (4.3 $\AA)$, could be minimized through hydrophobicity of the molecular sieve and the matrix (silica). The interplay of size exclusion and surface affinity thus provides highly selective adsorption suitable for sensor applications.

The QCM used in the present study is an AT-cut 6-MHz piezoelectric resonator, with $0.20 \mathrm{~cm}^{2}$ gold electrodes deposited on chromium underlayers on opposite sides of the crystal. The sensitivity of the QCM according to the Sauerbrey relationship ${ }^{5}$ is $12.3 \mathrm{ng} \mathrm{Hz}^{-1} \mathrm{~cm}^{-2}$. The electrode surface area resulting from the surface roughness evaluated by nitrogen sorption isotherms at $-196^{\circ} \mathrm{C}$ is 2.60 $\mathrm{cm}^{2} / \mathrm{cm}^{2}$.

The preparation of the microporous layer involved two steps: First, silicalite crystals (about 3- $\mu$ m diameter) were chemically anchored to the QCM gold electrodes via a thiol-organosilane coupling layer. ${ }^{4}$ Silicalite is a crystalline molecular sieve of approximate composition $\mathrm{SiO}_{2}$ with a pore system of zigzag channels along $A$ (free cross section ca. $5.1 \times 5.5 \AA)$, linked by straight channels along $B(5.3$ $\times 5.6 \AA) .{ }^{6}$ The silicalite crystals bonded to the QCM electrodes were then further coated with an amorphous, porous silica layer, prepared via sol-gel processing from $\mathrm{Si}(\mathrm{OEt})_{4}{ }^{7}$ so that stable microporous thin films composites were obtained. ${ }^{8}$ Typical film compositions are $0.50 \mu \mathrm{g} / \mathrm{cm}^{2}$

* To whom correspondence should be addressed.

(1) For recent reviews see: (a) Janata, J. Anal. Chem. 1990, 62, 33r. (b) Hughes, R. C.; Ricco, A. J.; Butler, M. A.; Martin, S. J. Science 1991, 254,75 .

(2) (a) Bein, T.; Brown, K.; Frye, G. C.; Brinker, C. J. U.S. Patent Application 07/580,373, allowed on Jan 23, 1992, to be issued. (b) Bein, T.; Brown, K.; Frye, G. C.; Brinker, C. J. J. Am. Chem. Soc. 1989, 111, 7640.

(3) Bein, T.; Brown, K.; Brinker, C. J. Stud. Surf. Sci. Catal. 1989, 49, 887.

(4) Yan, Y.; Bein, T. J. Phys. Chem., in press.

(5) $\Delta f=-2 f_{0}^{2} \Delta m A^{-1}\left(\rho_{q} \mu_{q}\right)^{-1 / 2}$, where $\Delta f$ is frequency shift, $f_{0}$ the parent frequency of the QCM, $\Delta m$ the mass change in grams, $A$ the piezoelectrically active area in $\mathrm{cm}^{2}, \rho_{\mathrm{q}}$ the density $\left(2.648 \mathrm{~g} \mathrm{~cm}^{-3}\right)$, and $\mu_{\mathrm{q}}$ the shear modulus $\left(2.947 \times 10^{11} \mathrm{dyn} \mathrm{cm}^{-2}\right)$ for AT-cut quartz. See: Sauerbrey, G. Z. Phys. 1959, 155, 206 .

(6) (a) Flanigen, E. M.; Bennett, J. M.; Grose, R. W.; Cihen, J. P.; Patton, R. L.; Kirchner, R. M.; Smith, J. V. Nature 1978, 271, 512. (b) Meier, W. M.; Olson, D. H. Atlas of Zeolite Structure Types, 2nd ed.; Butterworth: London, 1987.

(7) Bein, T.; Yan, Y. U.S. Patent, in preparation. 


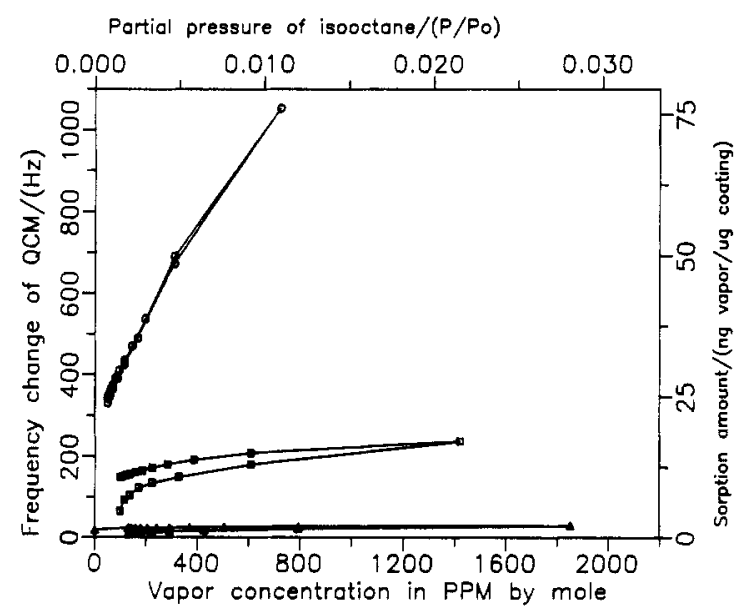

Figure 2. Dynamic sorption isotherms of ethanol (O), water $(\square)$ and isooctane $(\Delta)$ on QCM coated with $168 \mu \mathrm{g} / \mathrm{cm}^{2}$ of composite at $20^{\circ} \mathrm{C}$.

molecular coupling layer and $150 \mu \mathrm{g} / \mathrm{cm}^{2}$ silicalite with 6-8\% silica overlayer. The films have the following typical adsorption characteristics: Saturation of the micropores at $20^{\circ} \mathrm{C}$ (derived from $\alpha$ plots) was achieved with 0.115 $\mu \mathrm{g} /(\mu \mathrm{g}$ of film) of ethanol, corresponding to a microporosity of $0.146 \mathrm{~cm}^{3} / \mathrm{g}$. Nitrogen sorption at liquid nitrogen temperature on films presaturated with ethanol revealed a nitrogen monolayer capacity of $0.0028 \mu \mathrm{g} /(\mu \mathrm{g}$ of film $)$, corresponding to only $9.8 \mathrm{~m}^{2} / \mathrm{g}$ external surface area.

The selectivity and sensitivity of the composite filmcoated QCM devices were determined by measuring the dynamic vapor sorption isotherms and kinetics in a computer-controlled helium vapor flow system. Figure 1 shows the layout of the multiple vapor sorption apparatus. QCM frequency changes of $0.1 \mathrm{~Hz}$ could be detected with a Keithley 775A frequency counter interfaced to a 386-based personal computer. Equilibrium of the vapor sorption was assumed when the frequency changes were less than 1.0 $\mathrm{Hz}$ in $30 \mathrm{~s}$.

The highly selective vapor responses of the QCM coated with the microporous composite layer are illustrated by the sorption of pure vapors of ethanol (ca. 4.3- $\AA$ diameter), 2,2,3-trimethylpentane (isooctane, ca. $6.2 \AA$ ), and water $(2.65 \AA)$ in the range of $0-2000$ parts per million (ppm) (Figure 2). The QCMs were predegassed at $170^{\circ} \mathrm{C}$ in a helium flow for $20 \mathrm{~min}$. The sorption of ethanol (top curve) shows the largest and fairly linear response as a function of vapor concentration. A $50.4 \mathrm{ppm}$ ethanol vapor concentration results in $0.024 \mu \mathrm{g}$ of sorption $/ \mu \mathrm{g}$ of coating layer, $309 \mathrm{ppm}$ causes further mass increase to $0.050 \mu \mathrm{g} / \mu \mathrm{g}$, and $722 \mathrm{ppm}$ to $0.076 \mu \mathrm{g} / \mu \mathrm{g}$, which is about 1000 times higher than the alcohol response of a bare QCM.

In contrast, the response of the microdevice to isooctane (bottom line) exhibits an almost negligible change with increasing vapor concentration. As the concentration of isooctane is varied from $200 \mathrm{ppm}$ to $700 \mathrm{ppm}$, the amount adsorbed changes from 1.66 to $1.87 \mathrm{ng} / \mu \mathrm{g}$, which is a mass increment of only $0.6 \%$ of that of alcohol sorption at the same concentrations. Exclusion of 2,2-dimethylbutane from the microporous coating was also observed. The results show that novel sensing layers with highly effective molecular sieving functions and very low external surface areas can be designed. Sorption of the small water molecules (middle line) shows also a small response. Although

(8) Prior to formation of the sensing layer, the QCM substrates were stabilized by annealing at $450^{\circ} \mathrm{C}$ overnight, which resulted in frequency changes of $60-5 \mathrm{~Hz}$.

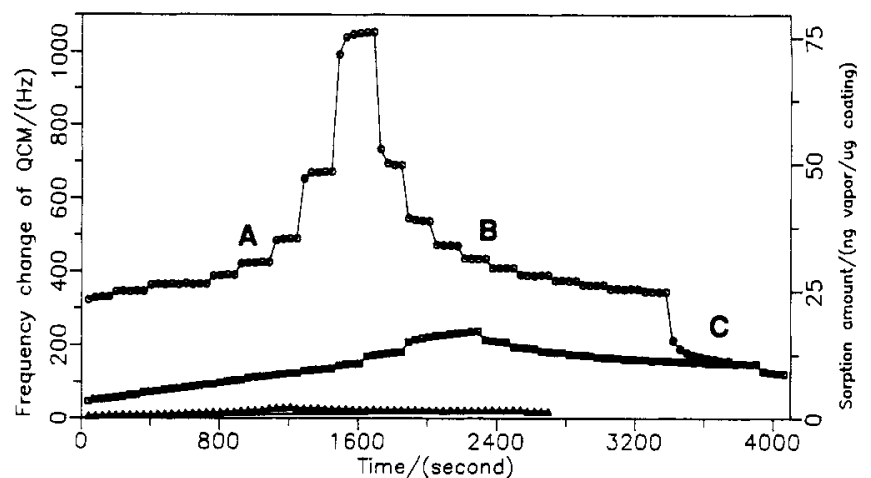

Figure 3. Dynamic sorption kinetics during sorption and desorption on the QCM described in Figure 2. Concentrations correspond to those in Figure 2 (interval times of $30 \mathrm{~s}$ ): ethanol $(O)$, water $(\square)$ and isooctane $(\Delta)$ at $20^{\circ} \mathrm{C}$.

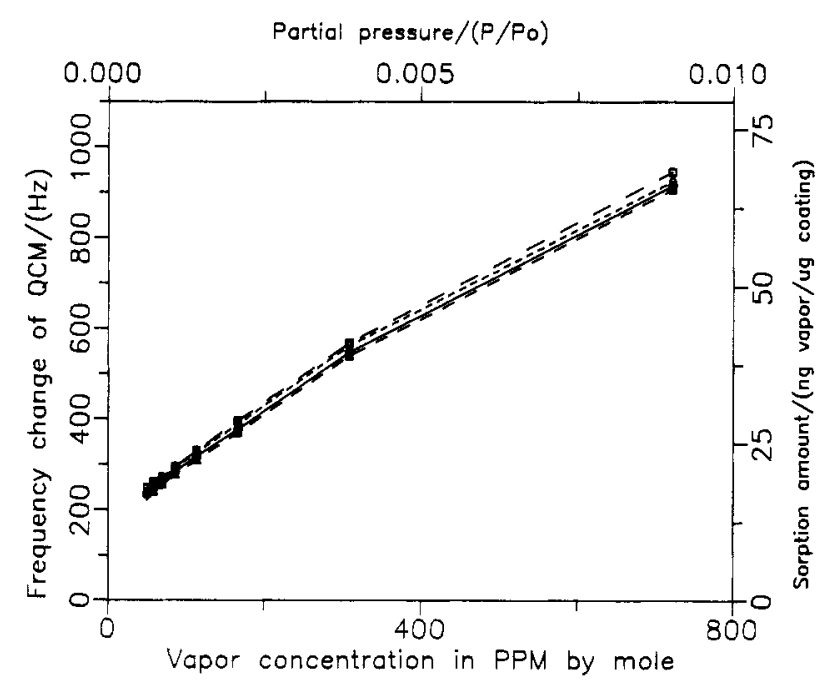

Figure 4. Dynamic sorption isotherms (at $20^{\circ} \mathrm{C}$ ) of ethanol vapor mixed with water and isooctane vapors on the sensing layer equilibrated with ambient air and purged at $20^{\circ} \mathrm{C}$. Sorption of 50-750 ppm ethanol (O); the same concentration range ethanol mixed with $66.3 \%$ water $(\square)$; the same concentration range ethanol mixed with $75.0 \%$ isooctane $(\Delta)$; the same concentration range ethanol mixed with $33.1 \%$ water and $50.1 \%$ isooctane $(\diamond)$.

water sorption slightly increases with increasing concentration (at the two concentrations given above, the capacity is respectively 12.2 and $15.5 \mathrm{ng} / \mu \mathrm{g}$ ), it already approaches a rectilinear isotherm at these low concentrations. This behavior differs drastically from the sorption of ethanol.

Figure 3 shows the fast equilibration of the QCM as a function of time with each point measured at 30-s intervals. If sorption and desorption at the same ethanol vapor concentrations (e.g., points A and B) are compared, very similar responses are observed. Water sorption on the degassed sensing layer is much less reversible under the experimental conditions. At the last desorption point $C$ of both ethanol and water, residual sorbates $(0.011 \mu \mathrm{g} / \mu \mathrm{g}$ for ethanol and $0.009 \mu \mathrm{g} / \mu \mathrm{g}$ for water) can be observed after the frequency changed less than $1 \mathrm{~Hz}$ within 30 -s intervals. A fraction of water molecules in the microporous film are more strongly bound than ethanol, probably to energetically heterogeneous sites related to metal cations and/or hydroxyl groups in the silicalite structure which can react with the sorbates. ${ }^{9-11}$

(9) Chen, N. Y. J. Phys. Chem. 1976, 80, 60

(10) Dubinin, M. M.; Rakhmatkariev, G. U.; Isirikyan, A. A., Translated from Izv. Akad. Nauk SSSR, Ser. Khim. 1990, 38, 1950.

(11) Jentys, A.; Warecka, G.; Derewinski, M.; Lercher, J. A. J. Phys. Chem. 1989, 93, 4837. 
We note that the amount of strongly sorbed molecules is only about $7 \%$ of the molecules needed to completely fill the microporous voids. Further experiments revealed that by purging the water-loaded crystals in $\mathrm{He}$ at $20^{\circ} \mathrm{C}$, a stable oscillation frequency of the QCM could be obtained in 5-10 min. This pretreatment leaves most of the void volume $(93 \% \pm 1 \%)$ accessible to ethanol and further reduces the water sorption capacity by ca. $50 \%$, as a result of saturating the reactive sites.

The selectivity of this preloaded QCM toward ethanol was studied in the presence of competing molecules (Figure 4). The response to pure ethanol is similar to that of a QCM completely degassed at elevated temperature. A high sorption capacity for ethanol $(0.017 \mathrm{vs} 0.024 \mu \mathrm{g} / \mu \mathrm{g}$ in the degassed film, at $50.4 \mathrm{ppm}$ vapor concentration) could still be observed. Sorption of a $75.0 \%$ isooctane $/ 25.0 \%$ ethanol mixture, at alcohol concentrations of 50.4 and $722 \mathrm{ppm}$, resulted in weight changes of 0.017 and $0.066 \mu \mathrm{g} / \mu \mathrm{g}$. These responses to the vapor mixture are almost the same as those to pure ethanol. Measurements of 18 sorption-desorption points for ethanol concentrations in the range $0-722 \mathrm{ppm}$ in isooctane show a standard deviation of only $0.4 \mathrm{ng} / \mu \mathrm{g}$ compared to pure ethanol responses. Sorption of a $33.1 \%$ water $/ 50.1 \%$ isooctane $/ 16.8 \%$ ethanol vapor mixture in the same alcohol concentration range only shows $1 \mathrm{ng} / \mu \mathrm{g}$ deviation. The results demonstrate that ethanol is preferentially adsorbed in competition with water or isooctane.

The nature of the hydrophobic sensing layer and the preferential adsorption of ethanol over water on the preloaded QCM can be understood by evaluating the isosteric heats of adsorption. ${ }^{12}$ Water sorption on a polar surface is through specific interactions with cations or hydroxyls. When such energetic sites (cations) are "blocked" by molecules presorbed in the sensing layer, the isosteric heat of adsorption of water over the range 8-14 $\mathrm{ng} / \mu \mathrm{g}$ in the sensing layer is about $6.6 \mathrm{kcal} \mathrm{mol}^{-1}$, substantially below that of the heat of liquefaction of water $\left(10.5 \mathrm{kcal} \mathrm{mol}^{-1}\right.$ at $25^{\circ} \mathrm{C}$ ) and similar to that reported for pure silicalite..$^{13}$ Thus it is energetically unfavorable for water to condense into such a system. In contrast, for ethanol an isosteric heat of $11 \mathrm{kcal} \mathrm{mol}^{-1}$ is obtained over a wide sorption range of $20-80 \mathrm{ng} / \mu \mathrm{g} .{ }^{10}$ This value is greater than the heat of liquefaction of ethanol $\left(10.1 \mathrm{kcal} \mathrm{mol}^{-1}\right.$ at $\left.25^{\circ} \mathrm{C}\right)$. The favorable sorption of ethanol vs water also illustrates that pronounced micropore filling by ethanol can occur at low concentrations. Finally, the chemical stability of the coated QCM devices was tested by exposing them to the vapors above $1 \mathrm{M} \mathrm{HCl}$ for $12 \mathrm{~h}$. The sorption behavior remained virtually unchanged after this treatment.

The microsensor design discussed in this communication shows that highly selective responses can be achieved when microporous adsorption is combined with tailored surface interactions in composite films. The only molecules that are expected to compete with ethanol adsorption are those small enough to enter the silicalite pores and with similar affinity to the intrazeolite surface, such as methanol. Ethanol sensing in applications such as fermentation would probably not be affected by such interferences. Further exploration of other selective interactions in microporous glass composites is in progress.

(12) The isosteric heats were obtained from the sorption isotherms in the range $0-40^{\circ} \mathrm{C}$ by the relation $Q_{\mathrm{Bt}}=R T_{1} T_{2} \ln \left(P_{1} / P_{2}\right)_{\mathrm{a}} /\left(T_{1}-T_{2}\right)$ where $P_{1}$ and $P_{2}$ are the equilibrium concentrations for the same sorption amount in the sensing layer, $a$, at the temperatures $T_{1}$ and $T_{2}$, respectively.

(13) An isosteric heat of $6 \mathrm{kcal} \mathrm{mol}^{-1}$ for water sorption was reported by Flanigen et al. in ref 6 , and an isosteric heat of $12-14 \mathrm{kcal} \mathrm{mol}^{-1}$ for ethanol was reported by Dubinin in ref 10 .
Acknowledgment. We appreciate the contributions of Ray Forrister and Kelly Brown to instrumentation and sensor development in our laboratory. Funding from the National Science Foundation (Division of Materials Research) and from the Department of Energy (New Mexico WERC program) for this research is gratefully acknowledged.

Registry No. Ethanol, 64-17-5; 2,2,3-trimethylpentane, 7732-18-5; water, 564-02-3.

Supplementary Material Available: Figure showing dynamic sorption kinetics of ethanol during sorption and desorption (1 page). Ordering information is given on any current masthead page.

\section{Microwave Frequency Behavior of the EPR Copper(II) Ion Pairs Spectrum Formed in CuCe Oxide}

Antoine Aboukais,* Abdelrhani Bennani, Cossi Faustin Aíssi, Michel Guelton, and Jacques C. Vedrine ${ }^{\dagger}$

\section{Laboratoire de Catalyse Hétérogène URA CNRS 402 \\ Université des Sciences et Technologies de Lille I 59655 Villeneuve d'Ascq Cedex, France \\ Received January 24, 1992 \\ Revised Manuscript Received May 28, 1992}

In previous work, ${ }^{1-3}$ it has been shown, mainly by EPR, that copper-cerium oxides $(\mathrm{Cu} / \mathrm{Ce}=0.01)$ contain $\mathrm{Cu}^{2+}$ ion pairs. Well-resolved EPR spectra of copper(II) ion pairs have been evidenced at either X-band $(9.3 \mathrm{GHz})$ or $\mathrm{Q}$-band $(35 \mathrm{GHz})$ frequencies. The hyperfine structure of the half-field signal $\left(\Delta m_{\mathrm{s}}=2\right)$ and the parallel and the perpendicular components of the normal-field signal $\left(\Delta m_{\mathrm{s}}\right.$ $=1$ ) have been observed. Since the EPR spectra of dimers have been seldom studied at Q-band frequency, the purpose of this work is to show some anomalous behavior of a copper(II) ion pairs spectrum with the variation of the microwave frequency of the spectrometer.

The $\mathrm{CuCe}$ Oxide sample with an atomic ratio $\mathrm{Cu} / \mathrm{Ce}=$ 0.01 was prepared by calcination of the coprecipitated hydroxides of cerium and copper at $1173 \mathrm{~K}$ for $3 \mathrm{~h}$ under a flow of dry air.

The EPR spectra were obtained with a Varian (V-4502) spectrometer using the $\mathrm{X}$ and $\mathrm{Q}$ bands as microwave frequencies. The spectra were recorded at 77 and $293 \mathrm{~K}$. The $g$ values were measured in comparison with DPPH $(g=$ 2.0036) or directly by measuring the magnetic field $\mathrm{H}$ and the microwave frequency $\nu$.

The EPR spectra of $\mathrm{CuCe}$ oxide $(\mathrm{Cu} / \mathrm{Ce}=0.01)$ recorded at X-and Q-band frequencies are shown in Figure 1. As it was indicated elsewhere ${ }^{1-3}$ these well-resolved spectra clearly demonstrate the existence of three signals:

One signal, $\mathrm{K}$, corresponds to copper(II) ion pairs. In fact, the seven components with relative intensities 1:2:3:4:3:2:1 of the hyperfine splitting with two identical nuclei $\mathrm{Cu}^{2+}$ of spin ${ }^{3} / 2$ observed for $g_{\|}$and $g_{\perp}$ and the weak

\footnotetext{
†'Institut de Recherche sur la Catalyse, CNRS, 2 Avenue Albert Einstein, 69626 Villeurbanne, France

(1) Aboukais, A.; Guelton, M.; Vedrine, J. C. C. R. Acad. Sci. Paris 1991, t313 (Série 2), 169.

(2) Aboukais, A.; Bennani, A.; Aissi, C. F.; Wrobel, G.; Guelton, M.; Vedrine, J. C. J. Chem. Soc., Faraday Trans 1992, 88, 615.

(3) Aboukais, A.; Bennani, A.; Aissi, C. F.; Wrobel, G.; Guelton, M. J. Chem. Soc., Faraday Trans. 1992, 88, 1321.
} 